\title{
The Colombian Scientific Journals and COLCIENCIAS' Public Policy
}

\author{
ANDRÉS ESCOBAR-ESPINOZA ${ }^{1}$ \\ Universidad de Cartagena \\ aescobare@unicartagena.edu.co \\ MENIS MERCADO-MEJIA ${ }^{2}$ \\ Universidad de Cartagena \\ mmercado2@unicartagena.edu.co
}

The evaluation of scientific journals in the National Bibliographic Index (IBN) has been a process of continuous improvement towards the strengthening of Colombian scientific journals. This process initiated at the end of 1990s, but it was only in 2001 when the first set of requirements and basic conditions were introduced. COLCIENCIAS (Departamento Administrativo de Ciencia, Tecnología e Innovación) started in 2002 and established four categories (A1, A2, B, C). In addition, the National Bibliographic Database (BBN) was conformed, along the Indexation Service for National Scientific Journals, and the Homologation Service for International Scientific Journals.

In 2002, 91 scientific journals were classified and indexed at the national level, and 10 years later, up to 466 scientific journals entered in the national classification system as a consequence of an editorial learning process in universities and research institutions (Publindex, 2013). Nevertheless, this outstanding growth came with low levels of international visibility and impact in the international scientific community, and to some extent, with endogamy. By this, it became necessary to strengthen journals' editorial processes in the following areas: scientific quality, editorial quality, stability, visibility and impact of publications (Publindex 2013).

Editorial management determines journals' scientific quality by setting a clear, standardized and rigorous not only the peer-review process, but also the documents' originality with emphasis on research documents. This virtuous circle is accomplished through an organized structure of the Editorial Board, the Editor-in-Chief and the Peer-Reviewers. 
The Journal's specific editorial norms, along with its institutional editorial guidelines, which should be public and easily accessible, guarantee that standard editorial criteria are accomplished. Timely publishing represents journal's stability, and is considered an important factor in the international evaluation process of scientific journals.

In the same line, scientific journals should be accessible for anyone or open access (Romero, 2013), which implies the need to set electronic versions through online portals, webpages, or even better, specialized editorial platforms to promote the international access to journals' content. Nevertheless, in order to have international scientific visibility in specialized databases, it requires an efficient editorial management which guarantees at least, stability, editorial and scientific quality.

With respect to the impact of scientific journals, the proposed model follows popular metrics (Journal Citations Report-JCR, Scimago Journal Ranking-SJR) that were developed by private multinational companies which refer to the analysis of citations of published articles in evaluated journals.

Nevertheless, the proposed evaluation model does not consider, in order to evaluate the scientific impact of journals, alternative metrics such as the one developed by Hirsch (2005) known popularly as the $\mathrm{H}$ index for individuals. Based on this, there were developed multiple versions in order to evaluate scientific impact (Ruane \& Tol, 2008; Gagolewski \& Grzegorzewski, 2009) and also another metrics were developed to measure scientific productivity and impact not only for individuals (Bras-Amoros et al., 2011; Silagadze, 2010).
The new set of rules proposed by COLCIENCIAS, require adjustments to institutional editorial policies in order to strengthen their journals' editorial processes and better increase their international visibility through appropriate scientific metrics in their specialized field.

It is clear that represents some steps forward to increase international exposure of Colombian journals. Results will be achieved as long as editorial teams and their institutions work closely to include their publications in international scientific networks. In the case of northern Colombia, to strengthen their scientific publications represent a priority for the region, contributing to the reduction of existing gaps with other provinces in the country.

In this regard, Panorama Económico Journal of Universidad de Cartagena, is improving continuously its editorial processes to assure its scientific quality, and in order to increase its visibility, it has launched the specialized editorial platform for open access, the Open Journal System (OJS), which allows online content of more than 220 published articles since 1993. In addition, it permits to have an efficient and transparent control of the documents and more important, of the editorial process. On the other hand, it is projected the inclusion of the journal in international specialized databases, and the measure of its scientific impact through citation metrics. The main objectives focus on consolidate journal's scientific quality and international visibility in national and international databases and directories. 


\section{REFERENCES}

Maria Bras-Amorós, Josep Domingo-Ferrer, Vicenç Torra (2011), "A bibliometric index based on the collaboration distance between cited and citing authors", Journal of Informetrics, 5 (2): 248-264. http://dx.doi. org/10.1016/j.joi.2010.11.001.

Gagolewski, M. \& P. Grzgorzewski (2009), "A Geometric approach to the construction of scientific impact indices", Scientometrics, 81(3): 617-634. http://dx.doi.org/10.1007/ s11192-008-2253-y

Hirsch, J. E. (2005), "An index to quantify an individual's scientific research output", Proceedings of the National Academy of Sciences USA, 102 (46): $\quad$ 16569-16572. http://dx.doi.org/10.1073/pnas.0507655102

Romero, Z. (2013), "Hacia un nuevo modelo de medición que refleje las capacidades investigativas de los colombianos", Revista Saber, Ciencia y Libertad, 8(2): 13-16.

Ruane, F. \& R. S. Tol (2008), "Rational (successive) $\mathrm{H}$-indices: An application to economics in the Republic of Ireland", Scientometrics, 75 (2): 395-495. http://dx.doi.org/10.1007/ s11192-007-1869-7

Publindex (2013). Nuevo Modelo de Indexación de Publicaciones Seriadas de CTI-Publindex. Bogotá: Colciencias.

Silagadze, S.K. (2010). "Citation entropy and research impact estimation", Acta Physica Polonica Series B, 41:2325-2333. 
